\title{
Carrot (Daucus Carota L.) Peels Extract as an Herbal Corrosion Inhibitor for Mild Steel in $1 \mathrm{M} \mathrm{HCl} \mathrm{Solution}$
}

\author{
Mohammed Tariq Saeed ${ }^{1}$, Muhammad Saleem ${ }^{2}$, Aeshah Hussain Niyazi ${ }^{1}$, Faisal Ahmad Al-Shamrani ${ }^{1}$, Nawaf \\ Abdulelah Jazzar ${ }^{2} \&$ Mehmood $\mathrm{Ali}^{3}$ \\ ${ }^{1}$ General Studies Department, Jubail University College, Jubail Industrial City, Saudi Arabia \\ ${ }^{2}$ Department of Civil Engineering, Jubail University College, Jubail Industrial City, Saudi Arabia \\ ${ }^{3}$ Department of Environmental Engineering, NED University of Engineering \& Technology, Karachi, Pakistan \\ Correspondence: Muhammad Saleem, Department of Civil Engineering, Jubail University College, Jubail \\ Industrial City 31961, Saudi Arabia.
}

Received: January 2, 2020

doi:10.5539/mas.v14n2p97
Accepted: January 28, 2020

Online Published: January 31, 2020

URL: https://doi.org/10.5539/mas.v14n2p97

\begin{abstract}
The inhibition of corrosion on mild steel in $1 \mathrm{M} \mathrm{HCl}$ solution was evaluated by utilizing carrot (Daucus carota L.) peels (CP) extract. Study performed by gravimetric and Potentiodynamic polarization techniques. Various concentrations of CP extracts ranging from $0.05,0.1,0.2,0.3,0.4$, and $0.5(\mathrm{v} / \mathrm{v})$ were used and corrosion rate (CR) on mild steel and inhibition efficiency (IE) were investigated at three temperatures $(298 \mathrm{~K}, 308 \mathrm{~K}$, and $323 \mathrm{~K})$. Corrosion rate increase with the increase in temperature. As inhibitor concentration increases, corrosion rate decreases and IE decreases at elevated temperature. The substantial reduction in $\mathrm{CR}$ with the increase in the concentration of $\mathrm{CP}$ extract was noted at studied temperatures. However, the increase in the $\mathrm{CR}$ at each $\mathrm{CP}$ extract along with the increase in the temperature tallied to the increase in kinetic activities at the electrolyte and metal interface. Results show that with the increase of $0.5 \mathrm{~g} / \mathrm{l} \mathrm{CP}$ extract, about 3 times lower CR of mild steel at studied temperatures than in pure $1 \mathrm{M} \mathrm{HCl}$ solution affirm its robust inhibitive efficiency. Comparatively large change in the anodic Tafel slope and gradual decline in CR with an increase in the CP extract concentration confirmed the restricted dissolution of mild steel. Surface examination suggest that a layer of inhibitor material adsorbed on the surface of mild steel at low temperature is responsible for high IE and this phenomenon is characterized as chemisorption. Weight loss data used to test three well known adsorption isotherm Langmuir, Temkin and Freundlich models and found that data is fitted well to all the models to certain extent however Freundlich Isotherm is found to be best fitted with as the correlation coefficient $\left(\mathrm{R}^{2}\right)$ values reaching to unity, which showed the applicability of the models to the process.
\end{abstract}

Keywords: corrosion inhibition, Daucus carota L., effect of temperatures, adsorption isotherms, chemisorption

\section{Introduction}

Manuscript in the following sections discuss the research studiues done in the past and recently related the development of corrosion inhibitors utilizing various herbal extracts. It also depicts the approach of the current study to evaluate new corrosion inhibitor in the material and methods section. Results and discussion section presents the results obtained from laboratory investigations and discussed the obtained results. Finally, study is summarized and specific conclusions are presented in the summary and conclusion section.

\subsection{A Global Problem Corrosion}

Corrosion of a metal is a major problem that has gained great concern among oil industry and the researchers (Khaled, 2003). In many cases, the corrosion of metal is the destruction of materials resulting from an exposure to the air or the surrounding environment. Mild steel is widely used in most of the industries due to its low cost and easily availability. Although there are various options to control corrosion, the utilizing corrosion inhibitors is most suitable method for inhibiting the metals corrosion (Verma et al., 2015). Generally, these inhibitors are material which can be added in small concentration to an environment. This will result in reduction in the corrosion rate on a metal surface. Corrosion inhibitor often play an important role in oil and gas extraction and always been consider to be the first line of defense against corrosion (Migahed and Al-Sabagh, 2009). 


\subsection{Development of Corrosion Inhibitors}

Numerus attempts have been made to develop corrosion inhibitors, and most of these ways resulting toxic compounds and environmentally hazardous material. Most of the corrosion inhibitors are synthetic chemical which are expensive and most of the time very hazardous to environment. Most of the efficient organic inhibitors are those compounds containing hetro-atoms such as oxygen, sulfur, nitrogen, and phosphorus which facilitae the adsorption on metal surface (Umoren et al., 2018). Recently, Ye et al., developed high efeciency corrosion inhibitor from N-doped citric acid. The inhibition efficiency exceeded $90 \%$. They reported that the sdsorption mechanism of inhibitor on steel surface was physicochemical (Ye et al., 2020). Similarly, Sainia et al., synthesized Polyvinylpyrrolidone Oxime (PVPO) to test its ability as a corrosion inhibitor for mild steel in $1 \mathrm{M}$ $\mathrm{H} 2 \mathrm{SO} 4$, at different concentrations and temperatures. The highest corrosion efficiency was found to be $88.39 \%$, with a concentration of $1000 \mathrm{ppm}$, and a temperature of $303 \mathrm{~K}$ (Sainia et al., 2020).

However, there are environment friendly inhibitors are available which demonstrate biodegradability and having no or very low toxicity (Saeed et al., 2019). There has been increasing search for green Eco-friendly corrosion inhibitors (Al-Senaibani, 2000). Utilization of several plant extracts found a place in the remedy of corrosion as they are environment friendly, abundantly available and source of renewable natural inhibitors. Researchers in the past explored various naturally available plant materials and tested the capability of their extracts to inhibit the corrosion of metals in acidic as well as in alkaline environments and these nontoxic replacements found to be compatible with current industrial technologies (Eddy and Odoemelam, 2009; El-Etre and Ali, 2017; Khadom et al., 2018). Due to their availability and relatively low cost, naturally substances find various applications in many fields. There are several reviews on the use of plant extracts as corrosion inhibitors (Migahed and Sabagh, 2009). The literature has shown that plant material such as Aloe Vera extraxt (Eddy \& Odoemelam 2009), Aquilaria Crassna Leavees Extract (Helen et al., 2014), Garli (Barreto et al., 2017), Holy Basil (Tulsi) (Kumpawat et al., 2012) and Ginger (Narenkumar et al., 2017) has potential as corrosive inhibitors. Effects of Aloe vera extract on corrosion and kinetics of corrosion process of zinc in $\mathrm{HCl}$ solution also studied (Abiola, 2010). Extract has been studies as nontoxic and eco-friendly corrosion inhibitor for Aluminum in acidic and alkaline solution. The corrosion impedeing effect of seed extracts of Cantaloupe on cast iron in $1 \mathrm{M} \mathrm{HCl}$ solution utilizing hydrogen evolution measurements and mass loss techniques showed good efficiency as corrosion inhibitor (Emran et al., 2015).

The inhibition behavior of Momordica charantia seeds (MCS) as an environmentally compatible corrosion inhibitor for P110SS steel was investigated in $3.5 \mathrm{wt} \% \mathrm{NaCl}$ saturated with $\mathrm{CO} 2$ solution by means of polarization curve, AC impedance, and scanning electrochemical spectroscopy (SECM) (Singh et al., 2013). Fruits extract of Momordica charantia (MCFE) was characterized using gas chromatography (GC), and mass spectrometry (MS) methods. The corrosion inhibition effect on mild steel in $1 \mathrm{M} \mathrm{HCl}$ solution utilizing MCFE was estimated using static electrochemical methods (Aijuan et al., 2019). Efficacy of seed extract of Momordica charantia on mild steel in $1 \mathrm{~N} \mathrm{HCl}$ environment using phytochemical studies also tested and promising results were obtained (Kavitha et al., 2017). Rosemary leaves extract used to protect aluminum and magnesium alloy in a $3 \% \mathrm{NaCl}$ solution at room temperature (Kliškić et al., 2000). Natural honey was used by El-Etre for corrosion inhibition to protect copper (El-Etre, 1998). The inhibitive effect of khillah seeds extract on SX 316 steel in $\mathrm{HCl}$ solution was evaluated and researchers analyzed the insoluble complexes formed as a layer due to the interaction between iron cations and khillah seed extract (El-Etre, 1998). Various plant extracts were tested by Zucchi and Omar as a corrosion inhibitors and corrosion inhibition was studied on steel utilizing Potentiodynamic polarization technique. They obtained promising results and reported that most of the extracts show the inhibition of efficiency of $88 \%-96 \%$ in $1 \mathrm{~N} \mathrm{HCl}$ and $2 \mathrm{~N} \mathrm{HCl}$ solution respectively. They reported that the demonstrated inhibition efficiency is attributed to the hydrolysis of the protein content of these plants (Zucchi and Omar, 1985). Umoren studied the effect of gum Arabic as a corrosion inhibitor on mild steel in $\mathrm{H} 2 \mathrm{SO} 4$ solution and reported good efficiency as a corrosion inhibitor (Umoren, 2008).

Yee reported the corrosion inhibition efficiency of honey and Rosmarinus officinalis L. on metals namely; aluminum, zinc, copper and iron was studied in sodium chloride and sodium sulphate solutions. The promising effect of extracted obtained when zinc was polarized sodium chloride and sodium sulphate solutions in which honey was used. Some cathodic inhibition was observed due to Rosemary extracts when the metal was polarized in sodium chloride solution (Yee, 2004). Most recently, Zaheer et al., utilized extract of Ammi visnaga L. Lam seeds and reported the increase in the inhibition efficiency with the concentration of the extract and extract demonstrated the inhibition efficiency up to $84 \%$ at a concentration of $1.0 \mathrm{~g} / \mathrm{L}$. The polarization measurements indicate that the examined extract acts as a mixed inhibitor with predominant anodic efficacy (Zaher et al., 2020). Similarly, Majd et al., tested Esfand seed extract as a green corrosion inhibitor and extract provided inhibition 
efeciency of $98.8 \%$ while using $300 \mathrm{mg} / \mathrm{l}$ extract (Majd et al., 2020).

\subsection{Carrot (Daucus carota L.) a Promising Corrosion Inhibitor}

Carrot, is known as Daucus carota L. belongs to Apiaceae family and is one of the important vegetable worldwide. Carrot contain carotenoids which is a bioactive compound includes $\beta$-carotene and $\alpha$-carotene. Consist of provitamin A., which shows an important role in antioxidants, anticancer activity (Fikselová et al., 2008). In addition to carotene DC are an excellent source of other phenolic compounds, which are both antioxidants. Kavitha reported The phytochemical screening proved that the plant extract is rich in protein, phenol, amino acids and tannins. These compounds contain oxygen and nitrogen atoms which are the center of metal adsorption (Kavitha and Gunavathy, 2014). The DC extract was found to be a good eco-friendly green inhibitor in $\mathrm{HCl}$ medium. The report stated that using the quantum chemical parameters, $\beta$-carotene shows an interaction effect with the metal surface (Kavitha and Gunavathy, 2014).

Above literature review, shows that the studies have been done on carrot however, information about carrot (Daucus carota L.) is limited and plant having great potential to investigate. The prime objective of the present study to test the potential of local Daucus carota $L$. as an effective nontoxic and ecofriendly corrosion inhibitor.

\section{Materials \& Methods}

\subsection{Specimen Preparation}

Corrosion study was performed on mild steel having percentage composition; Mn- $0.181, \mathrm{P}-0.017, \mathrm{Cr}-0.035$, C-0.16, Mo-0.054, Al-0.017, V-0.033, and remainder Fe. The coupons of dimension $2 \mathrm{~cm}$ x $2.5 \mathrm{~cm}$ x $0.1 \mathrm{~cm}$ were used for gravimetric measurements and coupons having area of $1 \mathrm{~cm}^{2}$ was exposed in electrochemical studies. The specimen was mechanically polished, their edges were abraded with fine grade emery paper and degreasing in acetone, and coupons were dried at room temperature before use.

\subsection{Carrot Peel (CP) Extract Preparation}

Local carrots were collected from one of the local market selling the local fruits and vegetables at Jubail city. Carrots were washed thoroughly to remove any contamination and then its peel removed with a sharp knife. Later CP dried for one week under sunlight. Later, it was dried in electric oven at $60{ }^{\circ} \mathrm{C}$ for $12 \mathrm{hr}$. The desiccated material was crushed in pastel and mortar and then grinded to make powder. Then $5 \mathrm{~g}$ of dried powder was stirred in $100 \mathrm{~mL}$ of $1 \mathrm{M} \mathrm{HCl}$ and slurry was left for 24 hours to digest and extract all compounds from peel powder. The mixture was finally extracted through filtration using whattsman filter paper. The filtrate was refluxed with alcohol for two hours. The alcohol extract was filtered and alcohol removed by distillation to evaporate and the alcohol extract was mixed with $1 \mathrm{M} \mathrm{HCl}$ extract. This stock solution was kept in refrigerator before conducting study. Further dilution was prepared as $0.05 \%, 0.1 \%, 0.2 \%, 0.3 \%, 0.4 \%$, and $0.5 \%(\mathrm{v} / \mathrm{v})$ from $\mathrm{CP}$ extract stock solution by using distilled water.

\subsection{Weight Loss Measurements}

Mild steel specimens were cleaned with acetone and dried in air followed by etching in 5\% concentrated hydrochloric acid $(\mathrm{HCl})$ for 30 seconds and weighed using a digital balance. The weight loss was determined by weighing the cleaned samples before and after hanging them into $100 \mathrm{ml}$ of acid solution with and without using various concentrations of the inhibitor. The inhibitor (CP extract) under test was mixed with the $1 \mathrm{M} \mathrm{HCl}$ solutions containing various amounts of extract $(0,0.05 \%, 0.1 \%, 0.2 \%, 0.3 \%, 0.4 \%$ and $0.5 \%)$. Each experiment was allowed to run for 6 hours. The weight loss measurement was done in triplicate with and without various concentration of $\mathrm{CP}$ inhibitor solution in $1 \mathrm{M} \mathrm{HCl}$ at studies temperature $298 \mathrm{~K}, 308 \mathrm{~K}$ and $323 \mathrm{~K}$ which is controlled thermodynamically.

In each experiment after exposure, the specimens were removed from the bottle and scrubbed with a bristle brush, rinsed in distilled water, acetone, air-dried and re-weighed to get the final weight. Weight loss measurement and Corrosion rate (CR) calculation were carried out as per standard method, ASTM PA 2012. The corrosion rate was calculated by using the following equation (1) (NACE, 2012).

$$
\text { Corrosion rate, } \mathrm{CR}(\mathrm{mm} / \mathrm{y})=87.6 \mathrm{~W} / \mathrm{DAT}
$$

Where: CR is corrosion rate in millimeter per year ( $\mathrm{mm} / \mathrm{y})$. W is the Weight loss $(\mathrm{mg}), \mathrm{A}$ is the Exposed area of coupon in $\mathrm{cm}^{2}$. $\mathrm{T}$ is the time of exposure of the metal in 6 hours. D is the density of metal $(7.866 \mathrm{~g} / \mathrm{cm} 3)$.

The \% inhibition efficiency (I.E) was calculated by using Eq. (2) (Alaneme et al., 2015):

$$
\text { I.E. } \%=\left(1-\mathrm{CR}_{\text {inhib }} / \mathrm{CR}_{\text {blank }}\right) \times 100
$$

Where $\mathrm{CR}_{\text {inhb }}$ and $\mathrm{CR}_{\text {blank }}$ correspond to the corrosion rates in the presence and absence of the encoded $\mathrm{CP}$ 
extract inhibitor concentration.

The surface coverage $(\Theta)$ was calculated by using Eq. (3) (Alaneme et al., 2016).

$$
\Theta=\left(1-\mathrm{CR}_{\text {inhib }} / \mathrm{CR}_{\text {blank }}\right)
$$

\subsection{Electrochemical Measurements}

\subsubsection{Tafel Extrapolation Method}

For Potentiodynamic polarization studies, mild steel coupons with an exposed area of $1 \mathrm{~cm}^{2}$ were used, and experiments were carried out (without \& with inhibitors at selected temperature of $298 \mathrm{~K}, 308 \mathrm{~K}$ and $323 \mathrm{~K}$ ) using different concentrations of inhibitor; from 0 to $0.5 \%$ with exposure time of $30 \mathrm{~min}$ (or until a steady-state open circuit potential was obtained). The electrochemical cell of $250 \mathrm{~mL}$ round bottom flask with three necks. The three electrodes were fixed in these three necks. The mild steel coupon act as working electrode; platinum electrode as counter electrode and a saturated calomel electrode (SCE) $/ \mathrm{HgCl}_{2}$ used as a reference electrode. All three electrodes were connected to a Potentiostat (CS series electrochemical workstation, CS 315). Potential range of $\pm 250 \mathrm{mV}$ with respect to open circuit potential and a scan rate of $0.5 \mathrm{mV} / \mathrm{s}$ was applied. Both anodic and cathodic polarization curves were recorded with and witout various concentration of inhibitor solution.

From polarization curves, the Tafel slopes, corrosion potentials and corrosion current densities were calculated. Corrosion rate obtained and inhibition efficiency was calculated by using the following formula (Ali et al., 2008).

$$
\text { I.E. } \%=\left(1-\mathrm{I}_{\text {(corr(inhib) }} / \mathrm{I}_{\text {(corr(blank) }}\right) \times 100
$$

$\mathrm{I}_{\text {corr(blank) }}$ and $\mathrm{I}_{\text {corr(inhibit) }}$ are densities of corrosion current in the absence and presence of the inhibitor, respectively.

The laboratory procedure described by Belloque et al., characterize the basic compound present in the CP extract. by IR and ${ }^{1} \mathrm{H}-\mathrm{NMR}$ spectroscopy (Belloque et al., 2000). The IR of the extract was run in $\mathrm{KBr}$ to identify the functional groups present in the compound of $\mathrm{CP}$ extract. and ${ }^{1} \mathrm{H}-\mathrm{NMR}$ was run in $\mathrm{CDCl} 3$ solvent to elucidate the structure of compound chlorogenic acid.

\subsubsection{Surface Examination}

The surface morphology of mild steel specimens was examined by immersing in various test solutions before and after exposure to1 $\mathrm{M} \mathrm{HCl}$ (blank) and with and without inhibitor of $0.5 \%$ concentration for a period of $6 \mathrm{hrs}$. The specimens were taken out and dried. Optical Microscope (Model Olympus BX51) was used to obtain the images of specimen surface.

\section{Results \& Discussion}

\subsection{Weight Loss Study Results}

The results of the weight loss measurements at three studied temperature $298 \mathrm{~K}, 308 \mathrm{~K}$ and $323 \mathrm{~K}$, after $6 \mathrm{~h}$ of immersion for inhibitor $(\mathrm{CP})$ and in blank $1 \mathrm{M} \mathrm{HCl}$ solution is presented in figure 1. Result shows that weight loss decrease as the concentration of inhibitor increased $(0 \%, 0.05 \%, 0.1 \%, 0.2 \%, 0.3 \%, 0.4 \%$ and $0.5 \%)$ at studied temperatures. Furthermore, the weight loss at any specific concentration showing increasing trend with the increase in temperature (i.e. $298 \mathrm{~K}<308 \mathrm{~K}<323 \mathrm{~K}$ ). It means that with the increase in temperature, the corrosion increases and metal is converted to metal oxide in the form of a layer on the metal surface which in turn decreases the mass of metal coupons. Similar observation is reported by researchers in the literature (Aijuan et al., 2019). At any one temperature with the concentration of inhibitor increased, the corrosion rate decreased and inhibition efficiency increased at all studied temperature. Similar results also reported elsewhere (Wetzstein et al., 2011). This may be attributed to the adsorption of extract constituents on the surface of mild steel and increase with the increase in concentration of inhibitor. This type of attachment is stronger and bonding is chemical in nature called as chemisorption (Bunrathep et al., 2007; Al - Sehaibani, 2000).

The variation in the corrosion rate in $\mathrm{mm}$ per year $(\mathrm{mm} / \mathrm{y})$ with the inhibitor concentration at three studies temperatures is presented in figure 2. Similarly, the variation in inhibition efficiency (IE) with the increase in inhibitor concentration at studies temperatures is presented in figure 3. It can be seen from figure 3 that the inhibition efficiency is increasing with the increase in inhibitor concentration however, decreasing with the increase in temperature. The I.E found to be $88.08 \%$ at $298 \mathrm{~K}, 86.39 \%$ at $308 \mathrm{~K}$ and $73.07 \%$ at $323 \mathrm{~K}$, while inhibitor conc. was $0.5 \%$ that attribute to the physisorption phenomenon. 


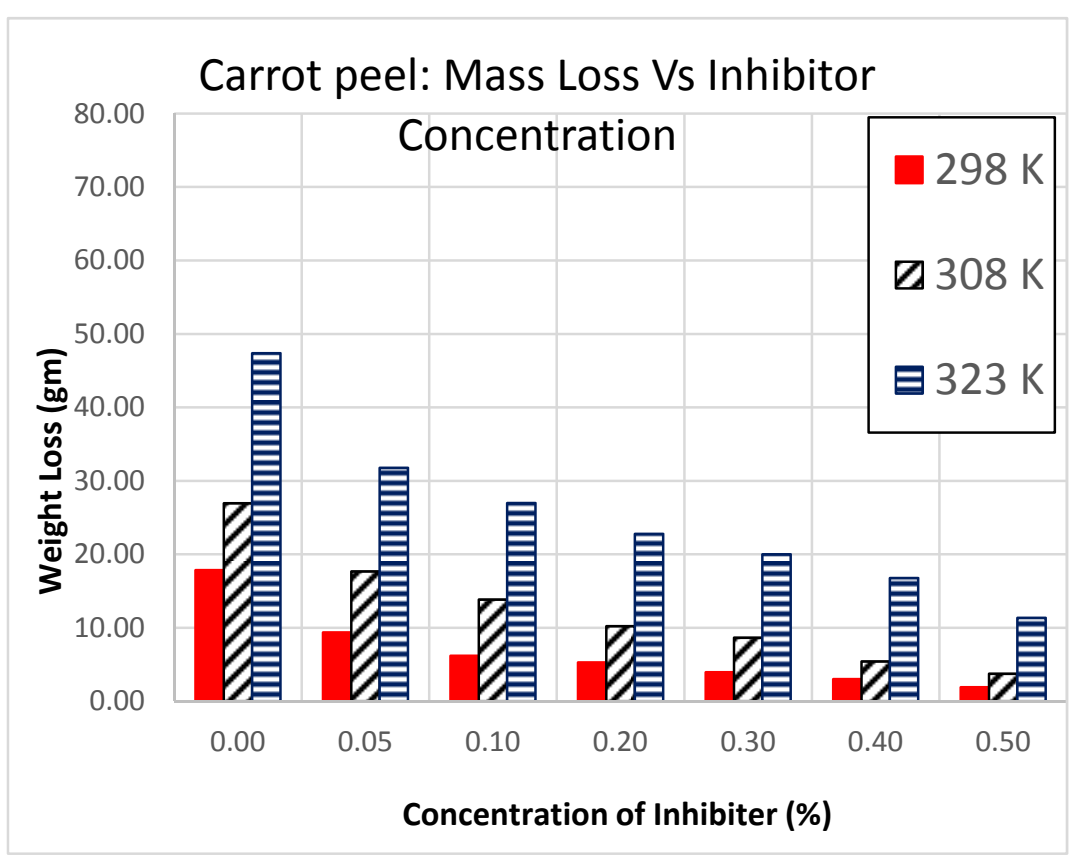

Figure 1. Weight loss Vs inhibitor concentration

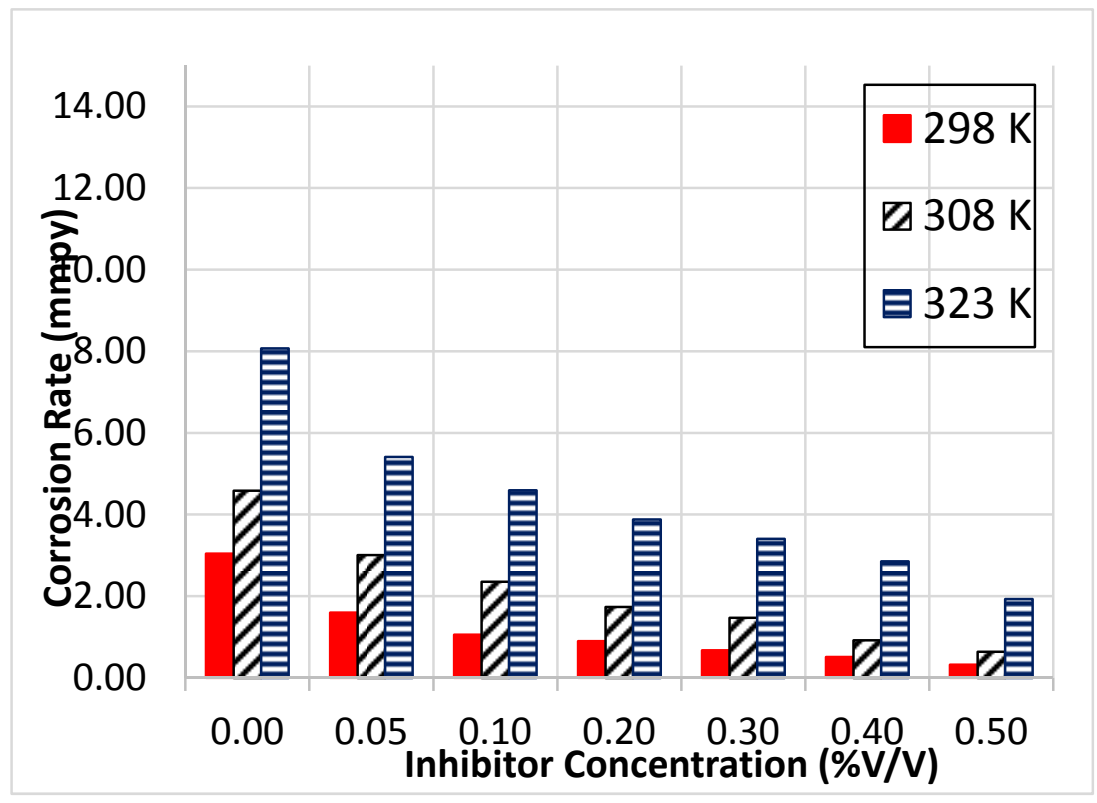

Figure 2. Corrosion rate Vs inhibitor concentration 


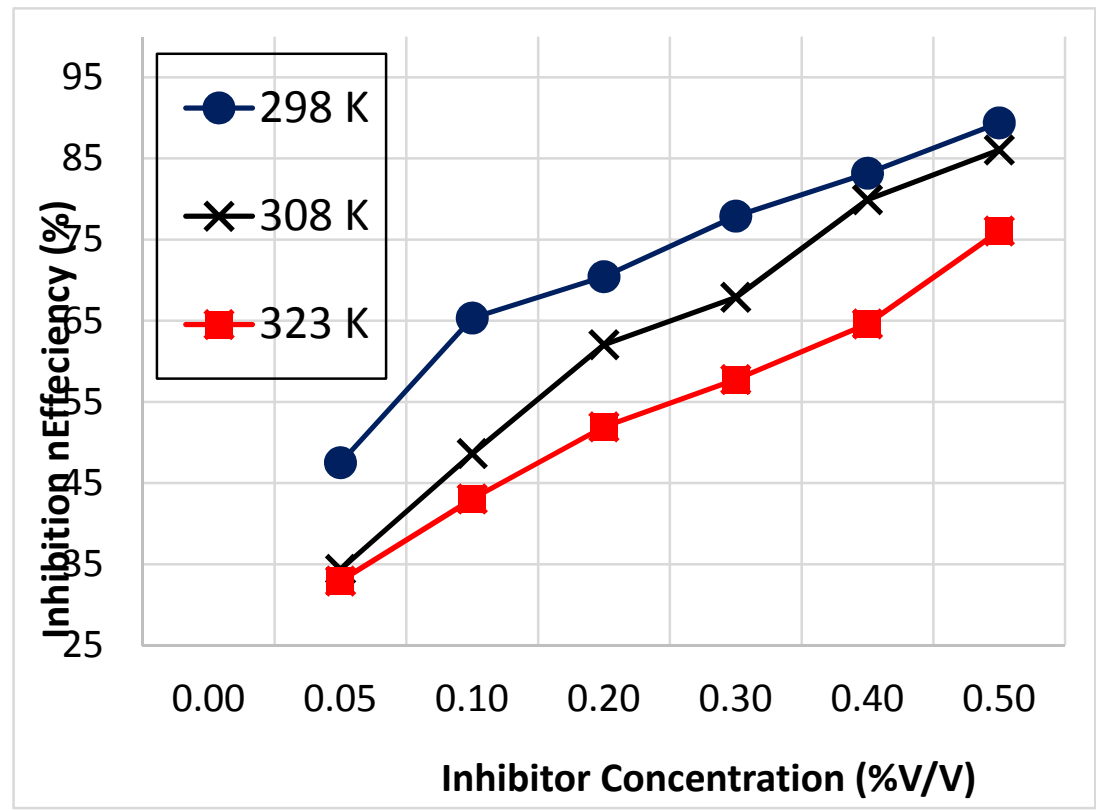

Figure 3. Inhibition efficiency Vs inhibitor concentration

\subsection{Electrochemical Measurements}

\subsubsection{Potentiodynamic Polarization Measurement}

The inhibitor was subjected to electrochemical study for the purpose of comparison with the gravimetric method. The electrochemical parameters, corrosion potential (Ecorr), corrosion current density (Icorr), anodic Tafel slope $(\beta a)$, cathodic Tafel slope $(\beta c)$, and the percentage inhibition efficiency (\% I.E), were calculted from the Tafel plots obtained from Potentiodynamic polarization experiments presented in figure $4(\mathrm{a}, \mathrm{b} \& \mathrm{c})$. The experiments were carried out in $1 \mathrm{M} \mathrm{HCl}$ solution with and without extract of $\mathrm{CP}$ as inhibitor in different concentration. The linear trend (Tafel region) obtained when $\log$ (I) vs potential (E) was used to determine the current density (Icorr) and Corrosion potential (Ecorr). Results obtained are summarized in table $1 \mathrm{a}, 1 \mathrm{~b}$ and $1 \mathrm{c}$ at studied temperatures $298 \mathrm{~K}, 308 \mathrm{~K}$ and $323 \mathrm{~K}$, respectively. The corrosion current was used to calculate corrosion rate (CR) in ( $\mathrm{mm} / \mathrm{y})$ and inhibition efficiency (I.E).

Generally, an inhibitor classified as anodic or cathodic inhibitor if the shift of Ecorr is more than $85 \mathrm{mV}$ with respect to blank solution (Yadav et al., 2014). The inhibitor works as a mixed - type inhibitor as the Ecorr shift were observed as less than that of blank as shown in the figures 4 . But at temperature $323 \mathrm{~K}$, the displacement of Ecorr was more than $85 \mathrm{mV}$ towards more negative that indicate the inhibitor is acting as cathodic inhibitor. The small shift in $\beta \mathrm{a}$ and $\beta \mathrm{c}$ indicate the inhibitor is mixed - type inhibitor (Helen et al., 2014).

After addition of $\mathrm{CP}$ extract inhibitor on mild steel in $1 \mathrm{M} \mathrm{HCl}$, there was no noticeable effect found on anodic Tafel slop ( $\beta \mathrm{a})$. The inhibitor acted as mixed inhibitor. When the $0.05 \% \mathrm{CP}$ extract was added to the solution then the dissolution tendency of steel in $1 \mathrm{M} \mathrm{HCl}$ solution was initially decreased rapidly from 2.8938 to 1.568 $\mathrm{mm} / \mathrm{y}$ (about $46 \%$ ) which further reduced to $0.3449 \mathrm{~mm} / \mathrm{y}$ at $0.5 \%$ CP extract concentration (about $88.1 \%$ ). Conversely, the cathodic Tafel slop $(\beta \mathrm{c})$ values found to be independent of $\mathrm{CP}$ extract concentration. When temperature increase from $308 \mathrm{~K}$ to $323 \mathrm{~K}$, the Icorr was found to be decrease along with $\mathrm{CP}$ concentration increased as given in table $3 \mathrm{~b}$ and $3 \mathrm{c}$. This phenomenan demonstrated that the layer of $\mathrm{CP}$ adsorbed on the metal surface and impede the formation of corrosion products on the metal surface and provide significant corrosion inhibition which is also evident from the decreasing CR results with the increase in the CP extract concentration. Similar to gravemetric measurement results, the CR in electrochemical testing increase from low to higher temperature (298K-323K), the inhibition efficiency (IE) decrease from $298 \mathrm{~K}$ to $323 \mathrm{~K}$ as concentration of CP increase from $0.05 \%$ to $0.5 \% \mathrm{~g} / \mathrm{L}$. Decrease in IE\% as temperature increase reveals that the Physisorption process take place, it means the dissolution process decrease as CP extract \% increase (Ali et al., 2008). The dissolution process increased as temperature increased. 
Table 1a. Kinetic parameter, Ecorr, Icorr, CR, and \%IE (Tafel scan results at $298 \mathrm{~K}$ )

\begin{tabular}{ccccccc}
\hline \multicolumn{7}{c}{ CP extract at Room temperature, 298K } \\
\hline & $\beta_{\mathrm{a}}(\mathrm{mV}$ & $\beta_{\mathrm{c}}(\mathrm{mV}$ & $I_{\text {corr }}$, & $E_{\text {corr, }}$ & $\mathrm{CR}$ & $\mathrm{IE} \%$ \\
& $\left.\mathrm{dec}^{-1}\right)$ & $\left.\mathrm{dec}^{-1}\right)$ & $\mathrm{A} / \mathrm{cm}^{2}$ & Volts & $(\mathrm{mm} / \mathrm{y})$ & \\
Blank & 74.534 & 132.59 & 0.00024668 & -0.46794 & 2.8938 & - \\
$0.05 \%$ & 73.163 & 131.12 & 0.00013451 & -0.47253 & 1.578 & 45.47 \\
$0.10 \%$ & 70.948 & 136.68 & 0.00008523 & -0.47044 & 0.99985 & 65.45 \\
$0.20 \%$ & 72.435 & 146.44 & 0.000072323 & -0.47513 & 0.84843 & 70.68 \\
$0.30 \%$ & 68.883 & 147.08 & 0.000051234 & -0.46608 & 0.60105 & 79.23 \\
$0.40 \%$ & 65.118 & 140.54 & 0.000039499 & -0.45952 & 0.46338 & 83.99 \\
$0.50 \%$ & 61.764 & 130.82 & 0.000029398 & -0.47152 & 0.34489 & 88.08 \\
\hline
\end{tabular}

Table 1b. Kinetic parameter, Ecorr, Icorr, CR, and \%IE (Tafel scan results at $308 \mathrm{~K}$ )

\begin{tabular}{|c|c|c|c|c|c|c|}
\hline \multicolumn{7}{|c|}{ CP Extract at, $308 \mathrm{~K}$} \\
\hline \multicolumn{7}{|c|}{ Electrochemical Study (Tafel) } \\
\hline & $\begin{array}{c}\beta_{\mathrm{a}}(\mathrm{mV} \\
\left.\operatorname{dec}^{-1}\right)\end{array}$ & $\begin{array}{c}\beta c(m V \\
\left.\operatorname{dec}^{-1}\right)\end{array}$ & $\begin{array}{l}\text { Icorr } \\
\mathrm{A} / \mathrm{cm}^{2}\end{array}$ & $\begin{array}{c}\text { Ecorr, } \\
\text { Volts }\end{array}$ & $\begin{array}{c}\mathrm{CR} \\
(\mathrm{mm} / \mathrm{y})\end{array}$ & IE \% \\
\hline Blank & 70.278 & 108.72 & 0.00037645 & -0.47097 & 4.4162 & - \\
\hline $0.05 \%$ & 78.931 & 131.3 & 0.0002795 & -0.47875 & 3.2789 & 25.75 \\
\hline $0.10 \%$ & 70.008 & 138.84 & 0.0001923 & -0.46689 & 2.2557 & 48.92 \\
\hline $0.20 \%$ & 66.194 & 107.09 & 0.0001418 & -0.47676 & 1.6638 & 62.33 \\
\hline $0.30 \%$ & 94.466 & 99.361 & 0.00008356 & -0.50054 & 0.98031 & 77.80 \\
\hline $0.40 \%$ & 64.958 & 115.89 & 0.00007087 & -0.4805 & 0.83145 & 81.17 \\
\hline $0.50 \%$ & 61.256 & 114.48 & 0.00005124 & -0.47679 & 0.60122 & 86.39 \\
\hline
\end{tabular}

Table 1c. Kinetic parameter, Ecorr, Icorr, CR, and \%IE (Tafel scan results at $323 \mathrm{~K}$ )

\begin{tabular}{|c|c|c|c|c|c|c|}
\hline \multicolumn{7}{|c|}{ CP Extract at $323 \mathrm{~K}$} \\
\hline \multicolumn{7}{|c|}{ Electrochemical Study (Tafel) } \\
\hline & $\begin{array}{c}\beta a(m V \\
\text { dec-1) }\end{array}$ & $\begin{array}{l}\beta c(m V \\
\text { dec-1) }\end{array}$ & $\begin{array}{l}\text { Icorr, } \\
\mathrm{A} / \mathrm{cm} 2\end{array}$ & $\begin{array}{l}\text { Ecorr, } \\
\text { Volts }\end{array}$ & $\begin{array}{c}\mathrm{CR} \\
(\mathrm{mm} / \mathrm{y})\end{array}$ & IE \% \\
\hline Blank & 77.418 & 122.07 & 0.00063932 & -0.47671 & 7.5 & - \\
\hline $0.05 \%$ & 77.473 & 167.01 & 0.0005952 & -0.48152 & 6.9827 & 6.90 \\
\hline $0.10 \%$ & 82.388 & 137.55 & 0.0005624 & -0.49161 & 6.5977 & 12.03 \\
\hline $0.20 \%$ & 73.834 & 135.9 & 0.0004616 & -0.46392 & 5.4159 & 27.79 \\
\hline $0.30 \%$ & 73.15 & 107.43 & 0.0004134 & -0.48062 & 4.8506 & 35.33 \\
\hline $0.40 \%$ & 72.306 & 117.87 & 0.00022857 & -0.49653 & 2.6814 & 64.25 \\
\hline $0.50 \%$ & 67.039 & 101.94 & 0.00016785 & -0.47776 & 1.9691 & 73.75 \\
\hline
\end{tabular}



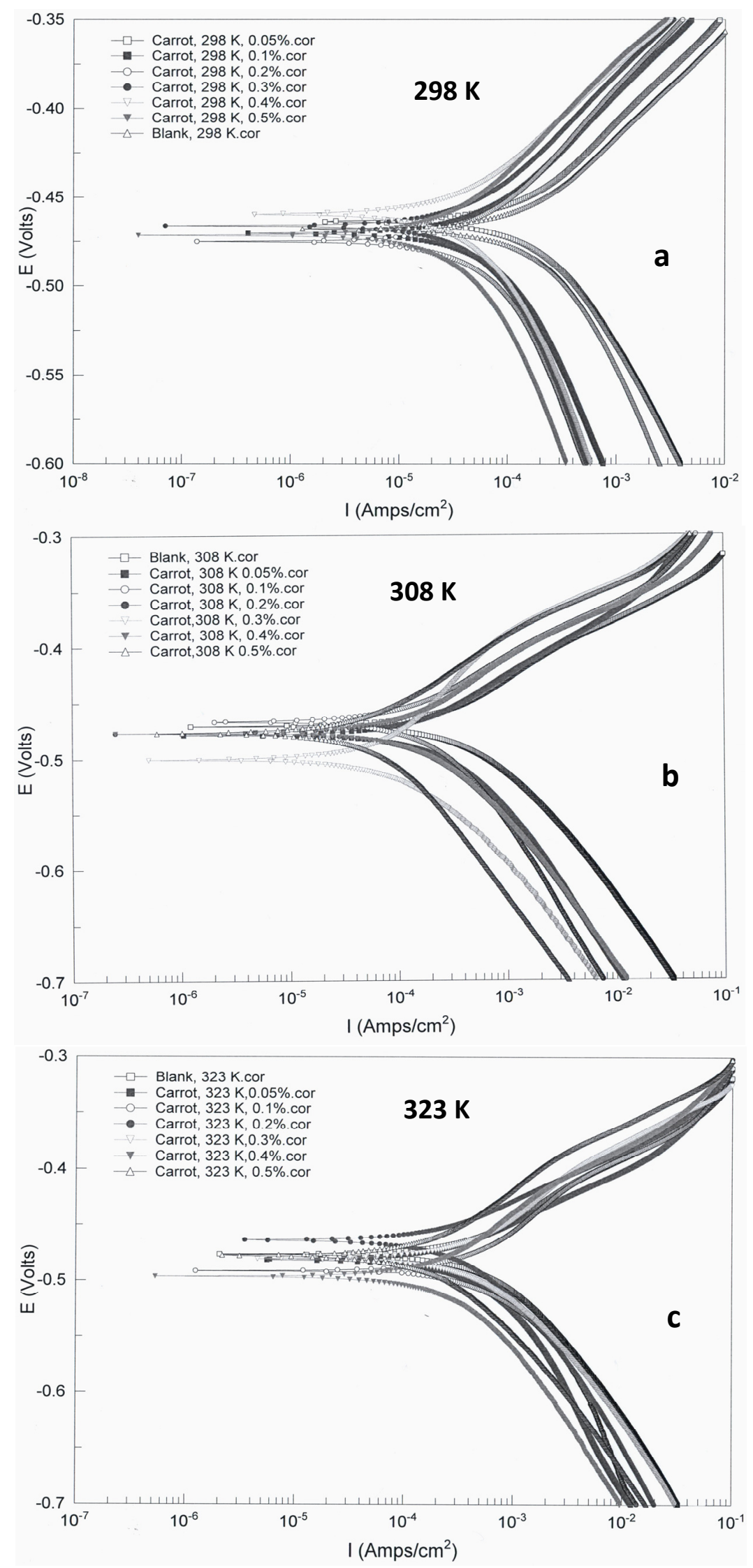

Figure 4. Tafel plots of CP extract at three studied temperatures, (a) 298K, b) $308 \mathrm{~K}$, and c) $323 \mathrm{~K}$ 


\subsection{Characterization of Structure of Compound}

Characterization of Structure of compound (Chlorogenic acid) present in CP extract utilizing IR and 1H-NMR is carried out. The structure of the compound of Chlorogenic acid of Carrot peel is presented in Figure 5.<smiles>O=C(/C=C/c1ccc(O)c(O)c1)O[C@@H]1C[C@](O)(C(=O)O)CC(O)C1O</smiles>

Figure 5. Structure of Chlorogenic acid present in the $\mathrm{CP}$ extract

\subsubsection{FTIR Spectroscopy}

The corrosion inhibitor having specific functional groups that contribute to the corrosion inhibition. The extract of inhibitor was analyzed for functional groups by FTIR. The IR spectra of the compound of the extract of Carrot peel $(\mathrm{CP})$ is presented in figure 6 .

IR frequencies of compound Chlorogenic Acid is given in table 2. The figure 6 shows the strong band adsorption at $3422 \mathrm{~cm}^{-1}$ which indicate the presence of $-\mathrm{OH}$ group. The presence of aliphatic asymmetric stretching of C-H shown at $2927 \mathrm{~cm}^{-1}$. The double bond $-\mathrm{C}=\mathrm{C}$ - of substituted alkene of aromatic ring showed at frequency of 1624 $\mathrm{cm}^{-1}$. The $-\mathrm{C}-\mathrm{O}$ of alcoholic group was appeared at frequency $1024 \mathrm{~cm}^{-1}$. The $-\mathrm{C}-\mathrm{H}-$ bending (substituted alkenes) appeared at $700 \mathrm{~cm}^{-1}$. These all functions groups play an important role in inhibiting the corrosion on mild steel in $1 \mathrm{M} \mathrm{HCl}$.

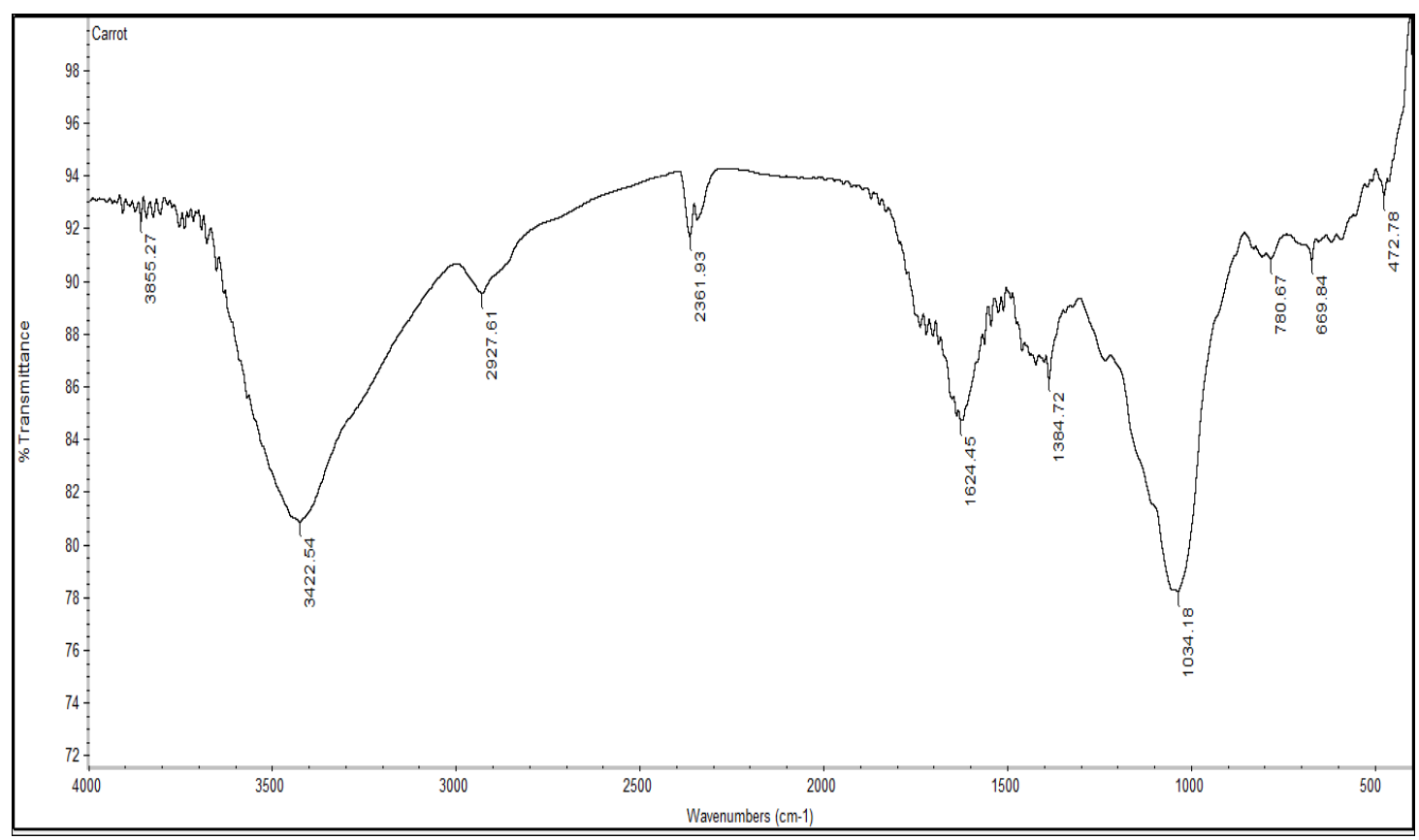

Figure 6. FTIR spectra of the extract of Carrot peel. (Daucus carota L.) 
Table 2. Typical infra-red (IR) absorption frequencies of the compound (Chlorogenic Acid).

\begin{tabular}{ccc}
\hline $\begin{array}{c}\text { Observed } \\
\text { frequency }\left(\mathrm{cm}^{-1}\right)\end{array}$ & $\begin{array}{c}\text { Possible Frequency range } \\
\left(\mathrm{cm}^{I}\right)\end{array}$ & Assignments \\
\hline 1) 3422 & $3200-3600$ & O-H stretching of alcohol \\
2) 2927 & $2910-3000$ & Asymmetric $-\mathrm{C}-\mathrm{H}$ stretching of alkanes \\
3) 2362 & $2350-25000$ & Symmetrical -C-H stretching of alkanes \\
4) 1624 & $1620-1680$ & $-\mathrm{C}=\mathrm{C}$ - stretching of substituted alkenes \\
5) 1024 & $1000-1260$ & $-\mathrm{C}-\mathrm{O}$ stretching of alcoholic region \\
6) 700 & $675-1000$ & $-\mathrm{C}-\mathrm{H}$ bending (substituted alkenes) \\
\hline
\end{tabular}

3.3.2 Nuclear magnetic resonance (1H-NMR) data of the compound (Chlorogenic Acid).

The polar compound Chlorogenic acid separated from CP powder (López-Martínez et al., 2015). The structure of compound was elucidated by 1H NMR (400 MHz, DMSO-D6). The peaks corresponding to all the protons whivh is present at different carbon in chlorogenic acid. The values of all the protons are given in table 3 in $\delta$ (ppm). The spectra was run in DMSO-D6 solvent.

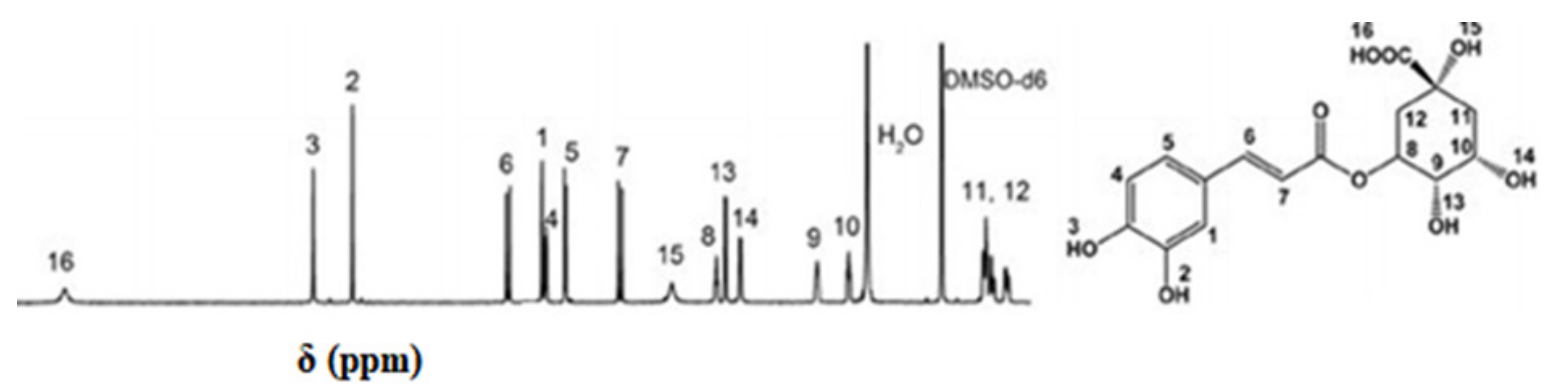

Figure 7. The Values of protons present in the Chlorogenic acid structure expressed in $\delta$ (ppm)

Table 3. Values of different protons present in the structure expressed in Delta ppm

\begin{tabular}{cc}
\hline Proton & $\delta(\mathrm{ppm})$ \\
\hline 1 & 7.04 \\
2 & 9.18 \\
3 & 9.62 \\
4 & 6.76 \\
5 & 6.99 \\
6 & 7.42 \\
7 & 6.15 \\
8 & 5.06 \\
9 & 3.91 \\
10 & 3.56 \\
$11-12$ & $2.04-1.74$ \\
13 & 4.96 \\
14 & 4.79 \\
15 & 5.56 \\
16 & 12.44 \\
\hline
\end{tabular}

\subsection{Surface Examination}

The polished mild steel coupons were immersed for $6 \mathrm{hrs}$ in $1 \mathrm{M} \mathrm{HCl}$ with $\mathrm{CP}$ inhibitor extract of $0.5 \%$ concentration at room temperature. These images were recorded and illustrated in figure 8 (A), (B), and (C). 
These images were seen under Optical microscope (Olympus BX 51) and found that there was substantial improvement on the surface of mild steels when inhibitor was present. The mild steel coupon, which was immersed in $1 \mathrm{M} \mathrm{HCl}$ without inhibitor, appeared to be heavily corroded when compared to the surface of mild steel in the presence of inhibitor. This may be due to the development of adsorbed protecting layer of constituent present in the inhibitor extract on the mild steel which impedes corrosion rate of metal appreciably.
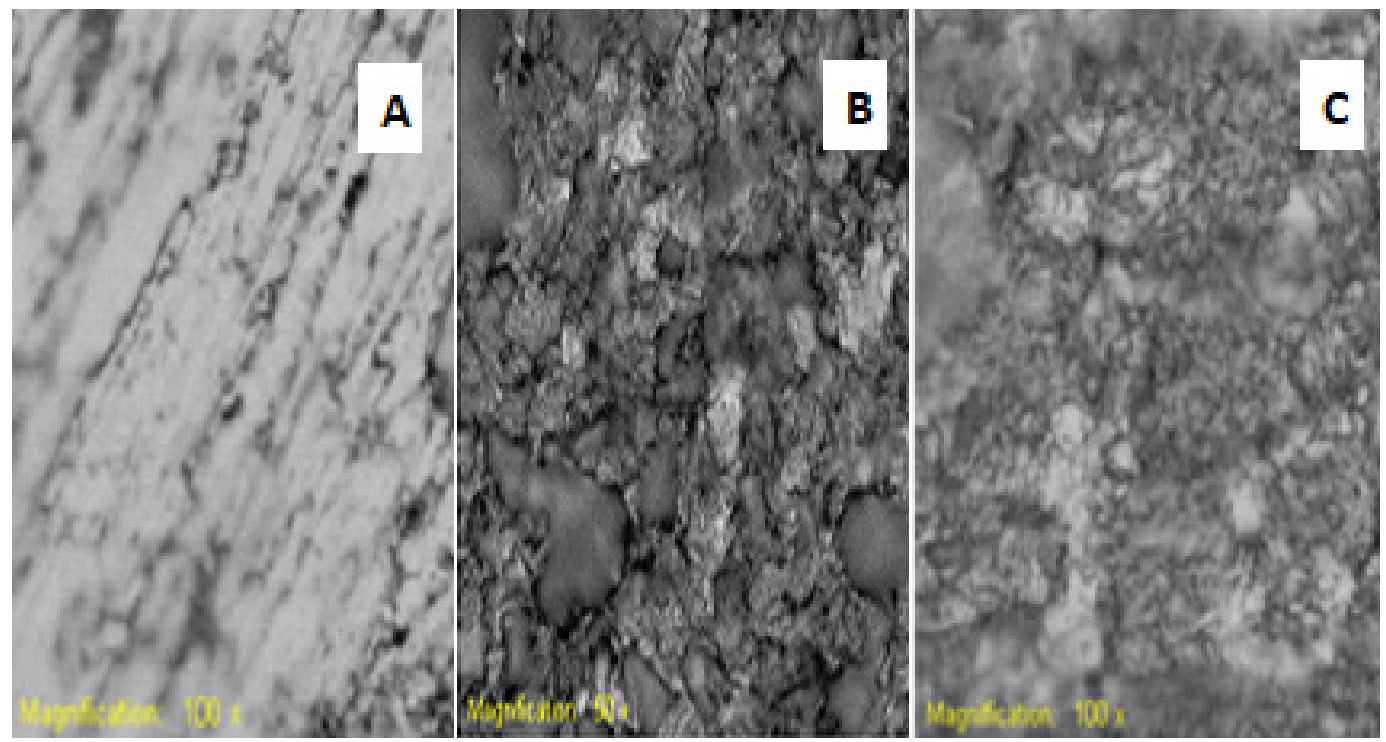

Figure 8. Optical Microscope images of mild steel coupon (a) Polished mild steel, (b) mild steel in 1M HCl (blank) (c) mild steel in $1 \mathrm{M} \mathrm{HCl}$ with $0.5 \%$ of $\mathrm{CP}$ inhibitor at room temperature

\subsection{Adsorption Isotherm}

The adsorption phenomena was generally evaluated by adsorption isotherm which is the relationship between the extents of adsorbate (x) adsorbed on the surface of adsorbent $(\mathrm{m})$ at certain pressure and at a constant temperature. The adsorption isotherm obtained from the results of weight loss study. In the adsorption studies Langmuir, Temkin and Freundlich isotherms are used frequently (Mead, 1981). Adsorption isotherms in the present study are employed to understand the inhibition mechanism of inhibitor on metal surface as they provide information about adsorbed molecules interactions with metal surface. Surface coverage values were determine from the weight loss data assuming that the inhibition efficiency (IE) to be directly proportional to the surface coverage $(\theta)$. The surface coverage data were than fitted to different adsorption isotherm models and appropriate model determined by evaluating the closeness of linear correlation coefficient $\left(\mathrm{R}^{2}\right)$ value to unity.

Based on the correlation coefficient values $\left(\mathrm{R}^{2}\right)$ presented in adsorption isotherms of figure 9 , almost in all cases value is approaching to unity and demonstrates the applicability of all the studied models to the process. However, the Freundlich adsorption isotherm found to be best describing the phenomenon as value of correlation coefficient reach to 0.9941 . 

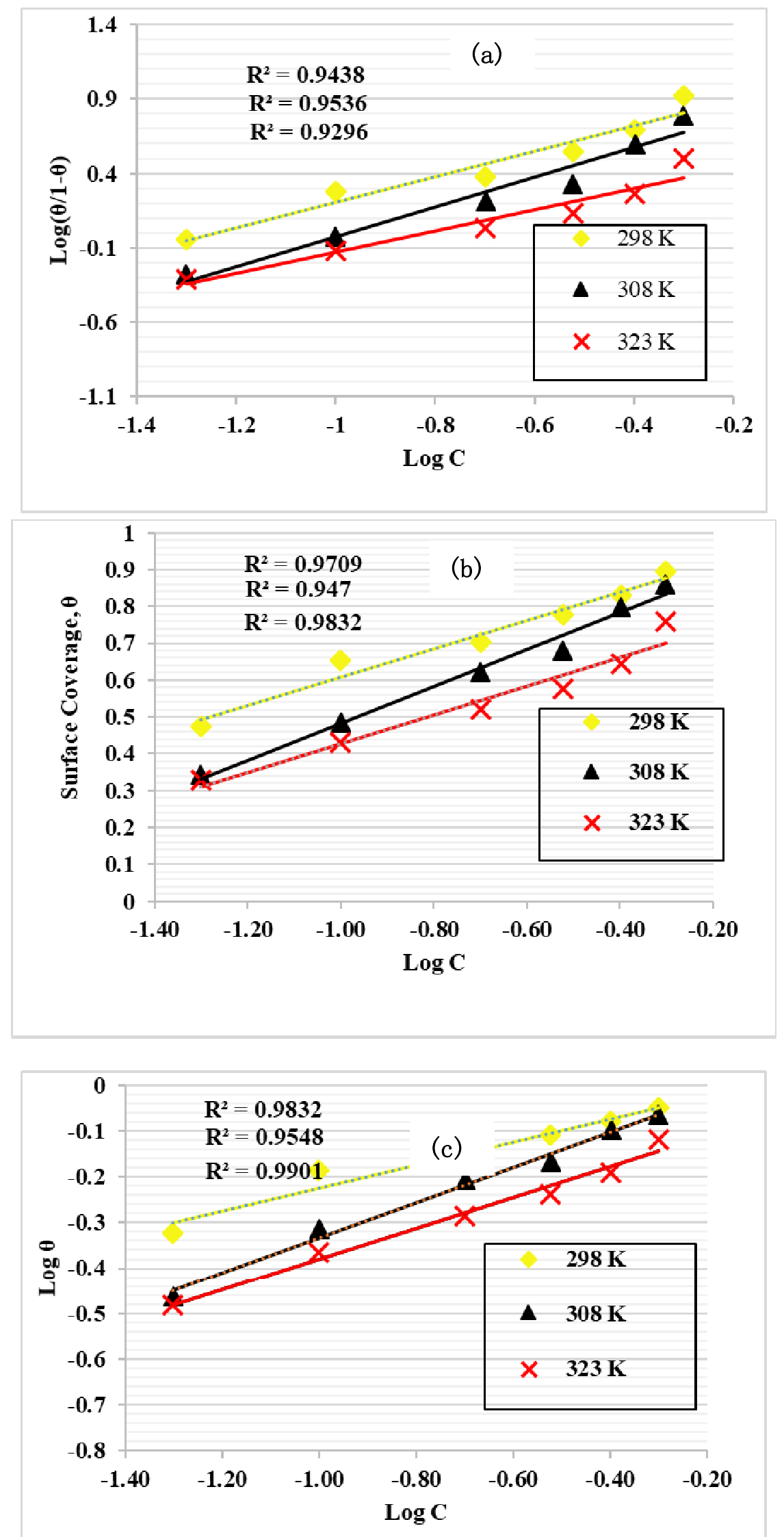

Figure 9. Adsorption isotherm models a) Langmuir, b) Temkin, and c) Freundlich 


\section{Summary \& Conclusions}

Current study assesses the Carrot peel extract as a potential corrosion inhibitor to protect the mild steel in acidic medium. The weight loss and electrochemical study reveal that the Carrot peel extract is efficient green corrosion inhibitor for mild steel in $1 \mathrm{M} \mathrm{HCl}$ environment.

The corrosion rate and inhibition efficiency strongly depends on the temperature variations. The inhibition efficiency increases with the increase in inhibitor concentration at each studied temperature $(298 \mathrm{~K}, 308 \mathrm{~K}$ and $323 \mathrm{~K}$ ) that attributes to the chemisorption phenomenon governed by the development of strong adsorbed layer on the metal surface. If the temperature increase from $298 \mathrm{~K}$ to $308 \mathrm{~K}$ then to $323 \mathrm{~K}$, the IE\% decrease at high temperature, respectively.

The IE increased from $45.47 \%$ to $88.08 \%$ when the concentration of CP extract increased from 0.05 to $0.5 \%$ in $1 \mathrm{M} \mathrm{HCl}$ solution at $298 \mathrm{~K}$. Similarly, at each studied temperature the reduction in CR and increase in IE demonstrated the strong inhibitive property of $\mathrm{CP}$ extract molecules in acidic solution. The IE at the highest CP extract concentration $(0.5 \%)$ was decreased from $88.08 \%$ to $73.75 \%$ with the increase in temperature from $298 \mathrm{~K}$ to $323 \mathrm{~K}$, respectively. This decrease in IE with the increasing temperature is attributes to the physisorption phenomenon which takes place on the surface of steel due to desorption process. Tafel polarization results demonstrated significant adsorption of $\mathrm{CP}$ extract molecules on the mild steel surface at each studied temperature.

Potentiodynamic polarization study shows that the extract is a mixed - type of inhibitor whose adsorption on mild steel is chemical adsorption at each studied temperatures but physical adsorption at high temperature. The Tafel polarization curve showing the shift of $\mathrm{E}_{\text {corr }}$ to less negative (anodic) compare to blank and also more negative (cathodic) compared to blank solution. The inhibiting effect of the studied extract could be attributed to the presence of chemical constituents present in the extract which is adsorbed on the surface of the mild steel.

The Carrot peel (Daucus carota L.) extract containing compound which contain many functional groups including alcoholic and carboxylic ketone and double bond identify by IR and the structure further characterized by $1 \mathrm{H}-\mathrm{NMR}$. These functional groups play important role in corrosion inhibition and show excellent activity against the corrosion on steel surface in $1 \mathrm{M} \mathrm{HCl}$. These functional groups interact with iron of steel make coordinate bonds that reduce the dissolution of steel and protect steel from corrosion at each temperature. The chemisorption phenomenon take place due to these interaction of functional groups on mild steel surface. Affecting both the anodic and cathodic reaction by simple blocking of the active metal sites.

The surface condition of specimen studied by Optical microscope (Olympus BX 51) shows that the surface is smoother in the presence of the extract in the corrosive environment. Therefore, the CP extract can be considered as potential and effective green corrosion inhibitor to protect the mild steel in acidic environment. The results of the weight loss method is in agreement with those obtained from electrochemical measurements.

Three adsorption isotherm models were used in this study namely; Langmuir, Temkin, and Freundlich to evaluate the best model describing the phenomena. Data of experimental study was fitted to each isotherm and the correlation coefficient $\left(R^{2}\right)$ values determined. As the $R^{2}$ values approaching unity in all cases shows the applicability of all the models to the process. However, the adsorption of the $\mathrm{CP}$ on the mild steel is best described by the Freundlich isotherm as indicated by values of $\mathrm{R}^{2}$ close to unity (at $0.5 \%$ inhibitor concentration). Therefore, the studied Saudi origin Carroty peel extract found to be a potential corrosion inhibitor for mild steel in acidic medium. Use of this inhibitor has two fold benefits, a green corrosion inhibitor and utilization of waste fruit peel as a beneficial raw material in addition to waste minimization.

Present study expected to contribute in the area of novel, effective, nontoxic and ecofriendly corrosion inhibitor development. Study will benefit the industries spending enormous amount of capital on corrosion prevetion. Study has academic value which may help the researchers to conduct further studies in the future to improve the inhibition efeciency significantly.

\section{Acknowledgments}

Authors are greatful to the Jubail University College for providing financial as well as technical support to complete this work.

\section{References}

Abiola, O. K., \& James, A. O. (2010). The effects of Aloe vera extract on corrosion and kinetics of corrosion process of zinc in $\mathrm{HCl}$ solution. Corrosion Science, 52(2), 661-664. https://doi.org/10.1016/j.corsci.2009.10.026 
Aijuan Z., Haijie S., Lingxia C., \& Yufang H. (2019). Electrochemical Studies of Bitter Gourd (Momordica charantia) fruits as Ecofriendly Corrosion Inhibitor for Mild Steel in $1 \mathrm{M} \mathrm{HCl} \mathrm{Solution.} \mathrm{Int} \mathrm{J.} \mathrm{Electrochem}$ Sci. 14, 6814-6825. https://doi.org/10.20964/2019.07.75

Alaneme, K. K., Daramola, Y. S., Olusegun, S. J., \& Afolabi, A. S. (2015). Corrosion inhibition and adsorption characteristics of rice husk extracts on mild steel immersed in 1M $\mathrm{H} 2 \mathrm{SO} 4$ and $\mathrm{HCl}$ solutions. International Journal of Electrochemical Science, 10(4), 3553-3567.

Alaneme, K. K., Olusegun, S. J., \& Adelowo, O. T. (2016). Corrosion inhibition and adsorption mechanism studies of Hunteria umbellata seed husk extracts on mild steel immersed in acidic solutions. Alexandria Engineering Journal, 55(1), 673-681. https://doi.org/10.1016/j.aej.2015.10.009

Ali, S. A., Al-Muallem, H. A., Rahman, S. U., \& Saeed, M. T. (2008). Bis-isoxazolidines: a new class of corrosion inhibitors of mild steel in acidic media. Corrosion Science, 50(11), 3070-3077. https://doi.org/10.1016/j.corsci.2008.08.011

Al-Sehaibani, H. (2000). Evaluation of extracts of henna leaves as environmentally friendly corrosion inhibitors for metals. Materialwissenschaft und Werkstofftechnik: Materials Science and Engineering Technology, 31(12), 1060-1063. https://doi.org/10.1002/1521-4052(200012)31:12<1060:AID-MAWE1060>3.0.CO;2-K

Barreto, L. S., Tokumoto, M. S., Guedes, I. C., Melo, H. G. D., Amado, F. D. R., \& Capelossi, V. R. (2017). Evaluation of the anticorrosion performance of peel garlic extract as corrosion inhibitor for ASTM 1020 carbon steel in acidic solution. Matéria (Rio de Janeiro), 22(3). https://doi.org/10.1590/s1517-707620170003.0186

Belloque, J., López-Fandiño, R., \& Smith, G. M. (2000). A 1H-NMR study on the effect of high pressures on $\beta$-lactoglobulin. Journal of agricultural and food chemistry, 48(9), 3906-3912. https://doi.org/10.1021/jf000241q

Bunrathep, S., Palanuvej, C., \& Ruangrungsi, N. (2007). Chemical compositions and ant-oxidative activities of essential oils from four Ocimum species endemic to Thailand. J Health Res, 21(3), 201-206.

Eddy, N. O., \& Odoemelam, S. A. (2009). Inhibition of corrosion of mild steel in acidic medium using ethanol extract of Aloe vera. Pigment \& Resin Technology, 38(2), 111-115. https://doi.org/10.1108/03699420910940617

El-Etre, A. Y. (1998). Natural honey as corrosion inhibitor for metals and alloys. I. Copper in neutral aqueous solution. Corrosion Science, 40(11), 1845-1850. https://doi.org/10.1016/S0010-938X(98)00082-1

El-Etre, A. Y., \& Ali, A. I. (2017). A novel green inhibitor for C-steel corrosion in $2.0 \mathrm{~mol} \cdot \mathrm{L}^{-} 1$ hydrochloric acid solution. Chinese Journal of Chemical Engineering, 25(3), 373-380. https://doi.org/10.1016/j.cjche.2016.08.017

Emran, K. M., Al-Ahmadi, A. O., Torjoman, B. A., Ahmed, N. M., \& Sheekh, S. N. (2015). Corrosion and corrosion inhibition of cast Iron in hydrochloric acid $(\mathrm{HCl})$ solution by cantaloupe (Cucumis melo) as green inhibitor. African Journal of Pure and Applied Chemistry, 9(3), 39-49. https://doi.org/10.5897/AJPAC2015.0607

Fikselová, M., Šilhár, S., Mareček, J., \& Frančáková, H. (2008). Extraction of carrot (Daucus carota L.) carotenes under different conditions. Czech Journal of Food Sciences, 26(4), 268-274. https://doi.org/10.17221/9/2008-CJFS

Helen, L. Y. S., Rahim, A. A., Saad, B., Saleh, M. I., \& Raja, P. B. (2014). Aquilaria crassna leaves extracts-a green corrosion inhibitor for mild steel in $1 \mathrm{M} \mathrm{HCl}$ medium. Int. J. Electrochem. Sci, 9, 830-846. http://citeseerx.ist.psu.edu/viewdoc/summary?doi=10.1.1.655.501

Kavitha V., Guanavathy Dr. N., \& Poovarasi S. (2017). Efficacy of seed extract of Momordica charantia on corrosion inhibition of mild steel in $1 \mathrm{~N} \mathrm{HCl}$ medium using phytochemical studies. Vol-3 Issue-4, IJARIIE-ISSN (O)-2395-4396.

Kavitha V., \& Gunavathy D. (2014). Evaluation of Daucus Carota Aerial Extract as Corrosion Inhibitor for Mild Steel in Hydrochloric Acid Medium. International Journal of Research in Advent Technology, 2(7), 146-154. https://pdfs.semanticscholar.org/853d/f9965dc153a656c9ab61c9c860d98c887505.pdf

Khadom, A. A., Abd, A. N., \& Ahmed, N. A. (2018). Xanthiumstrumarium leaves extracts as a friendly corrosion inhibitor of low carbon steel in hydrochloric acid: Kinetics and mathematical studies. South african journal of chemical engineering, 25, 13-21. https://doi.org/10.1016/j.sajce.2017.11.002 
Kliškić, M., Radošević, J., Gudić, S., \& Katalinić, V. (2000). Aqueous extract of Rosmarinus officinalis L. as inhibitor of Al-Mg alloy corrosion in chloride solution. Journal of applied electrochemistry, 30(7), 823-830. https://doi.org/10.1023/A:1004041530105

Kumpawat, N., Chaturvedi, A., \& Upadhyay, R. K. (2012). Comparative study of corrosion inhibition efficiency of naturally occurring ecofriendly varieties of holy basil (tulsi) for tin in HNO3 solution. Open Journal of Metal, 2(3), 68-70. https://doi.org/10.4236/ojmetal.2012.23010

López-Martínez, L. M., Santacruz-Ortega, H., Navarro, R. E., Sotelo-Mundo, R. R., \& González-Aguilar, G. A. (2015). A 1H NMR investigation of the interaction between phenolic acids found in Mango (Manguifera indica cv Ataulfo) and Papaya (Carica papaya cv Maradol) and 1, 1-diphenyl-2-picrylhydrazyl (DPPH) Free Radicals. PLoS One, 10(11), e0140242. https://doi.org/10.1371/journal.pone.0140242

Majd, M. T., Ramezanzadeh, M., Ramezanzadeh, B., \& Bahlakeh, G. (2020). Production of an environmentally stable anti-corrosion film based on Esfand seed extract molecules-metal cations: Integrated experimental and computer modeling approaches. Journal of hazardous materials, 382, 121029. https://doi.org/10.1016/j.jhazmat.2019.121029

Mead, J. A. (1981). A comparison of the Langmuir, Freundlich and Temkin equations to describe phosphate adsorption properties of soils. Soil Research, 19(3), 333-342. https://doi.org/10.1071/SR9810333

Migahed, M. A., \& Al-Sabagh, A. M. (2009). Beneficial role of surfactants as corrosion inhibitors in petroleum industry: a review article. Chemical Engineering Communications, 196(9), 1054-1075. https://doi.org/10.1080/00986440902897095

NACE, A. (2012). ASTMG31-12a Standard Guide for Laboratory Immersion Corrosion Testing of Metals. ASTM International, West Conshohocken, PA.

Narenkumar, J., Parthipan, P., Nanthini, A. U. R., Benelli, G., Murugan, K., \& Rajasekar, A. (2017). Ginger extract as green biocide to control microbial corrosion of mild steel. 3 Biotech, 7(2), 133. https://doi.org/10.1007/s13205-017-0783-9

Saeed, M. T., Saleem, M., Usmani, S., Malik, I. A., Al-Shammari, F. A., \& Deen, K. M. (2019). Corrosion inhibition of mild steel in $1 \mathrm{M} \mathrm{HCl}$ by sweet melon peel extract. Journal of King Saud University-Science. https://doi.org/10.1016/j.jksus.2019.01.013

Sainia, N., Kumaa, R., Pahujaa, P., Malika, R., Malika, R., Singhalb, S., \& Lataa, S. (2020). Exploring the Capability of Synthesized PVP-Oxime for Corrosion Inhibition of a Mild Steel Surface in a $1 \mathrm{MH} 2 \mathrm{so} 4$ Solution. Portugaliae Electrochimica Acta, 38(1), 43-58. https://doi.org/10.4152/pea.202001043

Singh, A., Lin, Y., Liu, W., Ebenso, E. E., \& Pan, J. (2013). Extract of Momordica charantia (Karela) seeds as corrosion inhibitor for P110SS steel in CO 2 saturated 3.5\% NaCl solution. Int. J. Electrochem. Sci, 8(12), $884-12$.

http://www.academia.edu/download/46163348/Extract_of_Momordica_charantia_Karela_20160602-6739qv8ce9.pdf.

Umoren, S. A. (2008). Inhibition of aluminium and mild steel corrosion in acidic medium using Gum Arabic. Cellulose, 15(5), 751. https://doi.org/10.1007/s10570-008-9226-4

Umoren, S. A., Solomon, M. M., Obot, I. B., \& Suleiman, R. K. (2018). Comparative studies on the corrosion inhibition efficacy of ethanolic extracts of date palm leaves and seeds on carbon steel corrosion in $15 \% \mathrm{HCl}$ solution. Journal of Adhesion Science and Technology, 32(17), 1934-1951. https://doi.org/10.1080/01694243.2018.1455797

Verma, C., Quraishi, M. A., \& Singh, A. (2015). 2-Amino-5-nitro-4, 6-diarylcyclohex-1-ene-1, 3, 3-tricarbonitriles as new and effective corrosion inhibitors for mild steel in $1 \mathrm{M} \mathrm{HCl}$ : Experimental and

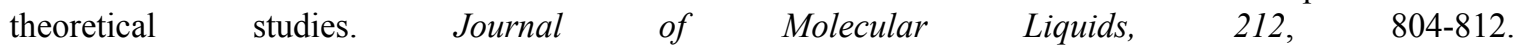
https://doi.org/10.1016/j.molliq.2015.10.026

Wetzstein, H., Ravid, N., Wilkins, E., \& Martinelli, A.D. (2011). A Morphological and Histological Characterization of Bisexual and Male Flower Types in Pomegranate. Journal of the American Society for Horticultural Science, 136(2), 83-92. https://doi.org/10.21273/JASHS.136.2.83

Yadav, M., Kumar, S., Bahadur, I., \& Ramjugernath, D. (2014). Electrochemical and quantum chemical studies on synthesized phenylazopyrimidone dyes as corrosion inhibitors for mild steel in a $15 \% \mathrm{HCl}$ solution. Int. J. Electrochem. Sci, 9, 3928-3950. 
Ye, Y., Yang, D., Chen, H., Guo, S., Yang, Q., Chen, L., \& Wang, L. (2020). A high-efficiency corrosion inhibitor of N-doped citric acid-based carbon dots for mild steel in hydrochloric acid environment. Journal of hazardous materials, 381, 121019. https://doi.org/10.1016/j.jhazmat.2019.121019

Yee, Y. J. (2004). Green inhibitors for corrosion control: a Study on the inhibitive effects of extracts of honey and rosmarinus officinalis L.(Rosemary) (Doctoral dissertation, MS thesis, University of Manchester, Institute of Science and Technology).

Zaher, A., Chaouiki, A., Salghi, R., Boukhraz, A., Bourkhiss, B., \& Ouhssine, M. (2020). Inhibition of Mild Steel Corrosion in 1M Hydrochloric Medium by the Methanolic Extract of Ammi visnaga L. Lam Seeds. International Journal of Corrosion, 2020. https://doi.org/10.1155/2020/9764206

Zucchi, F., \& Omar, I. H. (1985). Plant extracts as corrosion inhibitors of mild steel in HCl solutions. Surface Technology, 24(4), 391-399. https://doi.org/10.1016/0376-4583(85)90057-3

\section{Copyrights}

Copyright for this article is retained by the author(s), with first publication rights granted to the journal.

This is an open-access article distributed under the terms and conditions of the Creative Commons Attribution license (http://creativecommons.org/licenses/by/3.0/). 